\title{
Repetitive Transcranial Magnetic Stimulation for Treatment of Trichotillomania: Case Series
}

\author{
Efruz Pirdoğan Aydın, Jülide Güler Kenar, Aslı Tutan, Ömer Akil Özer, Kayıhan Oğuz Karamustafalıoğlu \\ Department of Psychiatry, Sisli Hamidiye Etfal Training and Research Hospital, Istanbul, Turkey
}

Trichotillomania is a psychiatric disorder characterised by compulsive pulling out of one's hair resulting in hair loss, which is included in the Diagnostic and Statistical Manual of Mental Disorders 5th edition category 'obsessive-compulsive disorder and related disorders'. Behavioural therapy and some medications are suggested for the treatment of trichotillomania, though these are not effective for all patients. Therefore, new treatment options are needed. Five female patients diagnosed with trichotillomania applied low-frequency repetitive transcranial magnetic stimulation (rTMS) over bilateral supplementary motor area for 3 weeks. Baseline and after rTMS, patients were given Beck Depression Inventory, Beck Anxiety Inventory and Massachusetts General Hospital Hair Pulling Scale to evaluate the severity of disorder at baseline and post-rTMS. In this case series, three of five patients with trichotillomania obtained a substantial benefit from treatment, while one patient obtained a partial symptom reduction. The last patient experienced a mild increase in severity of disease after rTMS treatment. rTMS treatment can be effective in some patients with trichotillomania and can be a promising option in treatment of trichotillomania.

KEY WORDS: Trichotillomania; Treatment; Transcranial magnetic stimulation; Motor cortex.

\section{INTRODUCTION}

Trichotillomania is a psychiatric disorder characterised by compulsive pulling out of one's hair resulting in hair loss, which is included in the Diagnostic and Statistical Manual of Mental Disorders 5th edition category 'obsessive-compulsive disorder (OCD) and related disorders' [1].

Trichotillomania has similarities with OCD in terms of phenomenology, comorbidity, familiarity, and possible neurobiology [2]. Hair pulling in trichotillomania, compulsions in OCD and motor tics in Tourette's syndrome are thought to result from deficits in motor inhibition processes [3]. A meta-analysis evaluating the treatments for trichotillomania showed that the behavioural therapies were effective, while olanzapine and $\mathrm{N}$-Acetyl Cysteine

Received: April 3, 2019/Revised: June 14, 2019

Accepted: June 27, 2019

Address for correspondence: Efruz Pirdoğan Aydın Department of Psychiatry, Sisli Hamidiye Etfal Training and Research Hospital, Halaskargazi Cad., Etfal Sok, 34371 Sisli, Istanbul, Turkey

E-mail: efruzpirdogan@gmail.com

ORCID: https://orcid.org/0000-0001-6056-0075
(NAC) could be potentially effective [4]. However, there are no US Food and Drug Administration-approved medications in treatment of trichotillomania and the proposed medications are not effective for all patients. Therefore, new treatment options are needed.

Repetitive transcranial magnetic stimulation (rTMS) is a non-invasive brain stimulation therapy and recently applied over the supplementary motor area (SMA) at a low frequency was demonstrated to be effective in OCD $[5,6]$. In this case series, below-mentioned subjects with trichotillomania applied low-frequency rTMS over bilateral SMA for 3 weeks and the effectiveness of rTMS treatment was evaluated.

\section{CASE}

\section{Assessments and rTMS Procedure}

rTMS was applied as repetitive stimulation with a 70 $\mathrm{mm}$ figure-of-8 shaped coil (Magstim Rapid2; Magstim Co., Wales, UK). Coil was placed over pre-SMA (situated at $15 \%$ of the distance between nasion and inion anterior to the vertex on the sagittal plane) using International 10-

(c) This is an Open-Access article distributed under the terms of the Creative Commons Attribution Non-Commercial License (http://creativecommons.org/licenses/by-nc/4.0) which permits unrestricted non-commercial use, distribution, and reproduction in any medium, provided the original work is properly cited. 
20 electroencephalography system. All patients received 15 sessions of rTMS ( 5 sessions a week). Sessions were applied for 20 minutes with 1,200 pulses at a frequency of 1 $\mathrm{Hz}$ and an intensity of $100 \%$ MT. Patients were instructed on purpose and design of study and informed consents were obtained. This case series was approved by the local ethics committee of Şişli Hamidiye Etfal Training and Research Hospital (Number of commission agreement: 1276).

\section{Case 1}

A 21-year-old, single, female college student. She has been suffering from trichotillomania since 13 years of age and a patch of baldness was present on the right side of scalp. She was not aware of her hair pulling for most of the day. She was on treatment with methylphenidate $36 \mathrm{mg}$ for comorbid attention deficit hyperactivity disorder. Prior treatments for trichotillomania with fluoxetine $20 \mathrm{mg} /$ day and psychotherapy were found to provide no benefit for the patient. She refused to take medication and thus, rTMS was scheduled (Table 1). Prior to rTMS treatment, Massachusetts General Hospital Hair Pulling Scale (MGH-HP) score was 19/28, Beck Anxiety Inventory (BAI) score was 5 and Beck Depression Inventory (BDI) score was 10 . At the end of 3 weeks of treatment, MGH-HP score was 0 (100\% improvement), BAl score was 6 and BDI score was 13. She was still in remission at the 6-month control visit (Fig. 1).

\section{Case 2}

A 26-year-old, married, working female patient. She has been suffering from trichotillomania for 1 year and a patch of baldness was present at the frontal area of scalp. She was not aware of her hair pulling for most of the day. Her sister had trichotillomania. She reported that she used escitalopram $20 \mathrm{mg} /$ day for 3 months for treatment of adjustment disorder but obtained no benefit for trichotillomania (Table 1). Prior to rTMS treatment, MGH-HP score was 24/28, BAI score was 14 and BDI score was 23. At the end of 3 weeks of treatment, MGH-HP score was 6 (75\% improvement), BAI score was 12 and BDI score was 14. Patient was observed to obtain a substantial benefit from treatment. Patient dropped out because she went abroad after treatment (Fig. 1).

\section{Case 3}

A 19-year-old, single, non-working female patient. She has been suffering from trichotillomania since 13 years of age and a near total baldness was present on the scalp, for

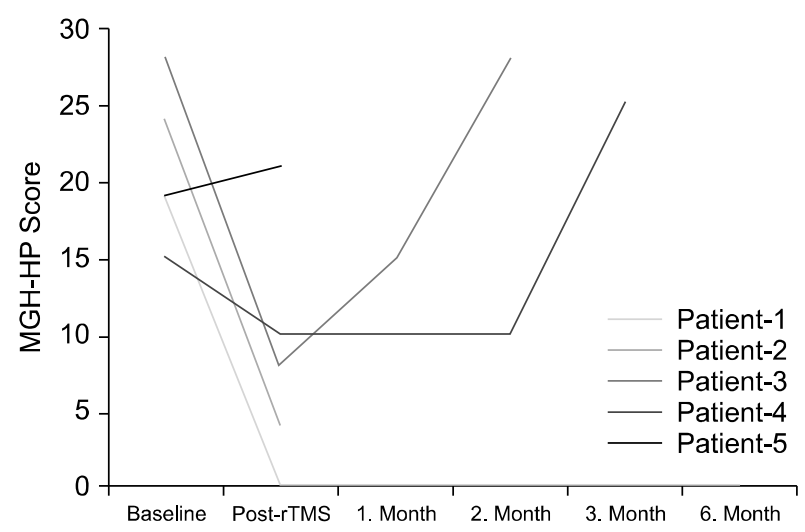

Fig. 1. Change of Massachusetts General Hospital Hair Pulling Scale (MGH-HP) scores from baseline to after repetitive transcranial magnetic stimulation (rTMS).

Table 1. Clinical features of the patients

\begin{tabular}{|c|c|c|c|c|c|c|c|c|c|c|}
\hline Case & $\begin{array}{l}\text { Age } \\
(y r)\end{array}$ & $\begin{array}{c}\text { Hair } \\
\text { pullingsites }\end{array}$ & $\begin{array}{c}\text { Type } \\
\text { ofpulling }\end{array}$ & $\begin{array}{c}\text { Age of } \\
\text { onset (yr) }\end{array}$ & Comorbidity & $\begin{array}{l}\text { Previous } \\
\text { therapies }\end{array}$ & $\begin{array}{c}\text { Current } \\
\text { medications }\end{array}$ & $\begin{array}{l}\text { MGH-HP } \\
\text { baseline }\end{array}$ & $\begin{array}{c}\text { BAI } \\
\text { baseline }\end{array}$ & $\begin{array}{c}\text { BDI } \\
\text { baseline }\end{array}$ \\
\hline Patient \#1 & 21 & Scalp & Automatic & 13 & ADHD & $\begin{array}{l}\text { Fluoxetine, } \\
\text { psychotherapy }\end{array}$ & $\begin{array}{l}\text { Methyl- } \\
\text { phenidate }\end{array}$ & 19 & 5 & 10 \\
\hline Patient \#2 & 26 & Scalp & Automatic & 25 & - & Escitalopram & None & 24 & 14 & 23 \\
\hline Patient \#3 & 19 & Scalp & Automatic & 13 & - & $\begin{array}{c}\text { NAC, behavioural } \\
\text { psychotherapy }\end{array}$ & Fluoxetine & 28 & 4 & 6 \\
\hline Patient \#4 & 23 & Scalp & Automatic & 19 & GAD & None & Fluoxetine & 15 & 23 & 6 \\
\hline Patient \#5 & 22 & $\begin{array}{l}\text { Eyebrows and } \\
\text { eyelashes }\end{array}$ & Focused & 12 & $\begin{array}{l}\text { Bipolar type IIOCD, } \\
\text { alcohol abuse, } \\
\text { specific phobia }\end{array}$ & None & $\begin{array}{l}\text { Sertralin, } \\
\text { aripiprazole, } \\
\text { quetiapine }\end{array}$ & 19 & 10 & 12 \\
\hline
\end{tabular}

MGH-HP, Massachusetts General Hospital Hair Pulling Scale; BAI, Beck Anxiety Inventory; BDI, Beck Depression Inventory; ADHD, attention deficit hyperactivity disorder; GAD, general anxiety disorder; OCD, obsessive compulsive disorder; NAC, N-Acetyl Cysteine. 
which she wore a wig. Patient stated that she was not aware of her hair pulling for most of the day. At the first visit, patient had severe major depression. Fluoxetine was initiated and increased to a dose of $80 \mathrm{mg}$ /day during follow-up. At the 3-month visit, remission was achieved in depression but no reduction was observed in severity of trichotillomania. Treatment with fluoxetine was continued and behavioural psychotherapy was initiated but the patient could not continue therapy because of lack of adherence. Thereafter, NAC 1,200 mg/day was initiated in combination with fluoxetine. At the 1-month visit, NAC was discontinued as patient obtained no benefit, and rTMS treatment was scheduled (Table 1). Prior to rTMS treatment, MGH-HP score was 28/28, BAI score was 4 and $\mathrm{BDI}$ score was 6 . At the end of 3 weeks of treatment, $\mathrm{MGH}-\mathrm{HP}$ score was 8 (70\% improvement), BAI score was 1 and BDI score was 2. Patient was observed to obtain a substantial benefit from treatment. No rTMS-related side effect occurred. At the 1-month visit, MGH-HP score increased to 15 and at the 2-month control visit, severity of disease increased with a MGH-HP score of 24/28 (Fig. 1).

\section{Case 4}

A 23-year-old, single, working female patient. She has been suffering from trichotillomania since 19 years of age and multiple bald patches were present on the scalp. She was not aware of her hair pulling for most of the day. Her mother had generalised anxiety disorder (GAD). Patient had comorbid GAD and onychophagia. She was on treatment with fluoxetine $20 \mathrm{mg} /$ day. Prior treatments with fluoxetine and observed no benefit (Table 1). Prior to rTMS treatment, MGH-HP score was 15/28, BAI score was 23 and BDI score was 6 . At the end of 3 weeks of treatment, MGH-HP score was 10 (33\% improvement), BAI score was 14 and BDI score was 7. "Flashes in the eye" lasted about 5-10 seconds occurred as a side effect following first 2-3 rTMS sessions but this side effect spontaneously regressed. Patient had a partial symptom reduction to treatment which was maintained for about 3 months and then, severity of hair pulling increased and patient returned to baseline (Fig. 1).

\section{Case 5}

A 22-year-old, single, non-working female patient. She has been suffering from trichotillomania since 12 years of age. Near total hair loss was present on her eyebrows and eyelashes, and she has had her eyebrows tattooed. She was aware of her hair pulling for most of the day. Her brother has been suffering from schizophrenia and her mother had a diagnosis of major depression. She had comorbid bipolar disorder type 2, OCD, alcohol abuse and specific phobia (blood), and was on treatment with sertraline $100 \mathrm{mg}$, aripiprazole $5 \mathrm{mg}$, and quetiapine $150 \mathrm{mg}$. She did not consult to a psychiatrist for treatment of trichotillomania but received medication for her comorbidities for a long period of time with no benefit for trichotillomania (Table 1). rTMS was scheduled for the patient. Prior to rTMS treatment, MGH-HP score was 19/28, BAI score was 10 and BDI score was 12 . At the end of 3 weeks of treatment, no reduction was observed in severity of hair pulling and MGH-HP score was 21 (no improvement), BAI score was 11 and BDI score was 11 (Fig. 1).

\section{DISCUSSION}

In this case series, three of five patients with trichotillomania obtained a substantial benefit from treatment, while one patient obtained a partial symptom reduction. The last patient experienced a mild increase in severity of disease after rTMS treatment. To the best of our knowledge, there is no study or case report investigating the effectiveness of rTMS treatment in trichotillomania.

There is no approved treatment and reported treatment algorithm for trichotillomania. Nevertheless, it is stated that the behavioural therapies can be used as first-line treatment [4]. Contrary to OCD, SRIs (clomipramine, fluvoxamine, escitalopram or fluoxetine) could not demonstrate convincing effectiveness in trichotillomania [7]. Olanzapine and NAC precede other treatments with respect to effectiveness in meta-analysis studies [4]. However, patients in our case series could obtain no benefit from use of certain SRI therapies, behavioural therapy, NAC and antipsychotic therapies and thus, rTMS treatment was scheduled.

rTMS treatment applied over SMA at a low frequency was demonstrated to be effective in OCD $[5,6]$. Mantovani et al. [5] concluded that the low-frequency rTMS application confers an inhibitory effect on hyperactivity in orbito-fronto-cortical circuits and normalises the activity in orbitofrontal cortex/SMA resulting in inhibition of intrusive thoughts, impulses, images and repetitive motor responses in OCD. As a result of the trichotillomania trials 
which detected some structural changes in many cortical areas and SMA region [8] and the tests which reported defects in motor response inhibition [9], impairments in motor inhibition processes have become focus in aetiology of trichotillomania. Therefore, SMA stimulation becomes important in neuromodulation studies in trichotillomania.

In our case series, rTMS treatment resulted in complete remission in Case 1 and ensured 75\%, 70\%, and 33\% reduction in severity of disorder in Case 2, Case 3, and Case 4 , respectively, whereas provided no benefit for Case 5. The lack of benefit in Case 5 might be caused by the patient's clinical presentation of focused hair pulling and the presence of multiple comorbidities such as bipolar disorder, OCD, alcohol abuse and specific phobia as confounding factors. As a result, 3 of 5 patients in our case series were responders. Previous randomised sham-controlled studies that applied low frequency rTMS over SMA in patients with OCD reported a response rate of $41-$ $67 \%$ and suggested that active rTMS was more effective than sham $[5,10]$. In another study involving 50 patients with treatment-resistant OCD, 25 patients were treated with rTMS over SMA, while the remaining 25 patients were treated with antipsychotic augmentation. Likewise, rTMS appeared to be effective in $2 / 3$ of patients with OCD, whereas only $1 / 4$ of patients were responders in antipsychotic augmentation group [11]. Hawken et al. [12] found a response rate of $80 \%$ and argued that this high rate might be resulted from placebo effect. On the contrary, a few studies reported that low frequency rTMS over SMA was not effective compared to sham in patients with OCD $[13,14]$. This inconsistency in the literature might be caused by the differences in number of rTMS sessions and clinical features of patients with OCD.

Limitations of the study include non-exclusion of psychiatric comorbidities, small sample size and lack of sham rTMS treatment. In conclusion, we believe that rTMS treatment can be effective in some patients with trichotillomania. Further double-blind randomised studies are needed to understand the effect of rTMS in patients with trichotillomania.

\section{Conflicts of Interest}

No potential conflict of interest relevant to this article was reported.

\section{Author Contributions}

Conceptualization: Efruz Pirdoğan Aydın, Jülide Güler Kenar. Data acquisition: Efruz Pirdoğan Aydın, Jülide Güler Kenar. rTMS application: Efruz Pirdoğan Aydın, Aslı tutan. Writing - original draft: Efruz Pirdoğan Aydın. Writing-review \& editing: Ömer Akil Özer, Kayıhan Oğuz Karamustafalıŏlu.

\section{ORCID}

Efruz Pirdoğan Aydın https://orcid.org/0000-0001-6056-0075 Jülide Güler Kenar https://orcid.org/0000-0002-9241-685X Aslı Tutan https://orcid.org/0000-0002-7418-5445

Ömer Akil Özer https://orcid.org/0000-0001-5565-4640 Kayıhan Oğuz Karamustafalıoğlu https://orcid.org/0000-0001-6151-7060

\section{REFERENCES}

1. American Psychiatric Association. Diagnostic and statistical manual of mental disorders: DSM-5. Arlington:American Psychiatric Association;2013.

2. Chamberlain SR, Odlaug BL, Boulougouris V, Fineberg NA, Grant JE. Trichotillomania: neurobiology and treatment. Neurosci Biobehav Rev 2009;33:831-842.

3. Chamberlain SR, Blackwell AD, Fineberg NA, Robbins TW, Sahakian BJ. The neuropsychology of obsessive compulsive disorder: the importance of failures in cognitive and behavioural inhibition as candidate endophenotypic markers. Neurosci Biobehav Rev 2005;29:399-419.

4. Slikboer R, Nedeljkovic M, Bowe SJ, Moulding R. A systematic review and meta-analysis of behaviourally based psychological interventions and pharmacological interventions for trichotillomania. Clin Psychol 2017;21:20-32.

5. Mantovani A, Simpson HB, Fallon BA, Rossi S, Lisanby SH. Randomized sham-controlled trial of repetitive transcranial magnetic stimulation in treatment-resistant obsessive-compulsive disorder. Int J Neuropsychopharmacol 2010;13:217-227.

6. Rehn S, Eslick GD, Brakoulias V. A meta-analysis of the effectiveness of different cortical targets used in repetitive transcranial magnetic stimulation (rTMS) for the treatment of obsessive-compulsive disorder (OCD). Psychiatr Q 2018;89: 645-665.

7. Jones G, Keuthen N, Greenberg E. Assessment and treatment of trichotillomania (hair pulling disorder) and excoriation (skin picking) disorder. Clin Dermatol 2018;36:728-736.

8. Snorrason I, Belleau EL, Woods DW. How related are hair pulling disorder (trichotillomania) and skin picking disorder? A review of evidence for comorbidity, similarities and shared etiology. Clin Psychol Rev 2012;32:618-629.

9. Chamberlain SR, Hampshire A, Menzies LA, Garyfallidis E, 
Grant JE, Odlaug BL, et al. Reduced brain white matter integrity in trichotillomania: a diffusion tensor imaging study. Arch Gen Psychiatry 2010;67:965-971.

10. Gomes PV, Brasil-Neto JP, Allam N, Rodrigues de Souza E. $A$ randomized, double-blind trial of repetitive transcranial magnetic stimulation in obsessive-compulsive disorder with three-month follow-up. I Neuropsychiatry Clin Neurosci 2012;24:437-443.

11. Pallanti S, Marras A, Salerno L, Makris N, Hollander E. Better than treated as usual: transcranial magnetic stimulation augmentation in selective serotonin reuptake inhibitor-refractory obsessive-compulsive disorder, mini-review and pilot openlabel trial. J Psychopharmacol 2016;30:568-578.
12. Hawken ER, Dilkov D, Kaludiev E, Simek S, Zhang F, Milev R. Transcranial magnetic stimulation of the supplementary motor area in the treatment of obsessive-compulsive disorder: a multi-site study. Int J Mol Sci 2016;17:420.

13. Pelissolo A, Harika-Germaneau G, Rachid F, Gaudeau-Bosma C, Tanguy ML, BenAdhira R, et al. Repetitive transcranial magnetic stimulation to supplementary motor area in refractory obsessive-compulsive disorder treatment: a shamcontrolled trial. Int J Neuropsychopharmacol 2016;19:pyw025.

14. Kang JI, Kim CH, Namkoong K, Lee Cl, Kim SJ. A randomized controlled study of sequentially applied repetitive transcranial magnetic stimulation in obsessive-compulsive disorder. J Clin Psychiatry 2009;70:1645-1651. 